\title{
INFORMATION
}

\section{HOW WORDS MEAN: LEXICAL CONCEPTS, COGNITIVE MODELS, AND MEANING CONSTRUCTION}

\author{
Vyvyan Evans \\ Oxford University Press, 2009, pp. xv+377 \\ Do Tuan Long* \\ Department of Language Training and Professional Development, VNU University of Languages \\ and International Studies, Pham Van Dong, Cau Giay, Hanoi, Vietnam

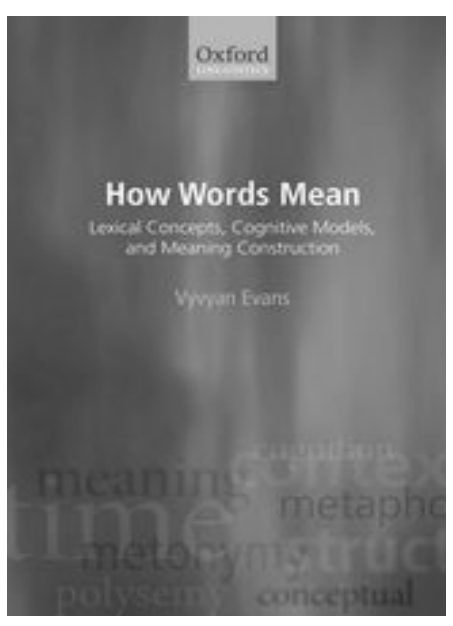 \\ The book "How Words Mean" by V. Evans (published in \\ 2009 by Oxford University Press) is a great achievement with \\ lots of principles and approaches integrated in order to deal with \\ a number of long standing and largely unsolved issues of lexical \\ semantics. In this book, the author tries to integrate different \\ cognitive approaches to grammar and semantics. Basically, \\ ideas presented by other researchers such as Lakoff \& Johnson \\ (1980, 1999), Langacker (1987), Croft (2002), Goldberg (2006) \\ and others are presented, and Evans then carefully and diligently \\ presents those theories and integrates them into his personal \\ conclusions, while adding new aspects. The theory is termed the \\ Theory of Lexical Concepts and Cognitive Models (LCCM for \\ short). The book is divided into five parts with 16 chapters, each \\ of which has an introduction and a summary. This helps readers \\ have a quick look at the main content of the chapter and find the \\ parts appealing to them.
}

\section{Introduction}

Chapter 1 lays the starting points for the book. Evans introduces the received view of word meaning, which he calls literalism and then criticizes it. The clear distinction between pragmatics and semantics causes the assumption that word meanings are stable and relatively delimited "atoms of meaning" which are context-independent. Instead, Evans argues that word meaning is variable in language use due to both encyclopedic knowledge and context of use. The second part of the book is for presenting lexical representation in LCCM.

\footnotetext{
${ }^{*}$ Tel.: 84-985227867

Email: tuanlongcfl@gmail.com
}

According to Evans, LCCM theory has a number of primary commitments:

- Lexical representations are points of access to encyclopedic knowledge.

- Encyclopedic knowledge is structured.

- Encyclopedic knowledge is dynamic.

- Encyclopedic knowledge is distinct from contextual information.

- There is no principled distinction between semantics and pragmatics.

As the name of the theory may denote, there are, basically, two key concepts in the theory: lexical concepts and cognitive models. In Evan's view, a lexical concept is a part of the linguistic knowledge that conveys various types of highly 
schematic linguistic content. Specifically, linguistic content includes information relating to the selectional tendencies associated with a given lexical concept - the range of collocational and collostructional behaviour of a given lexical concept. Evans supposes that because the lexical concept of an open-class word gives access to numerous association areas within the conceptual system, it also guides to access to numerous cognitive models. A cognitive model profile of a lexical concept is the range of cognitive models to which it facilitates direct access, and the range of additional cognitive models to which it therefore facilitates indirect access.

The following figure and table provide an overview of the architecture of LCCM Theory and key terms in LCCM respectively.

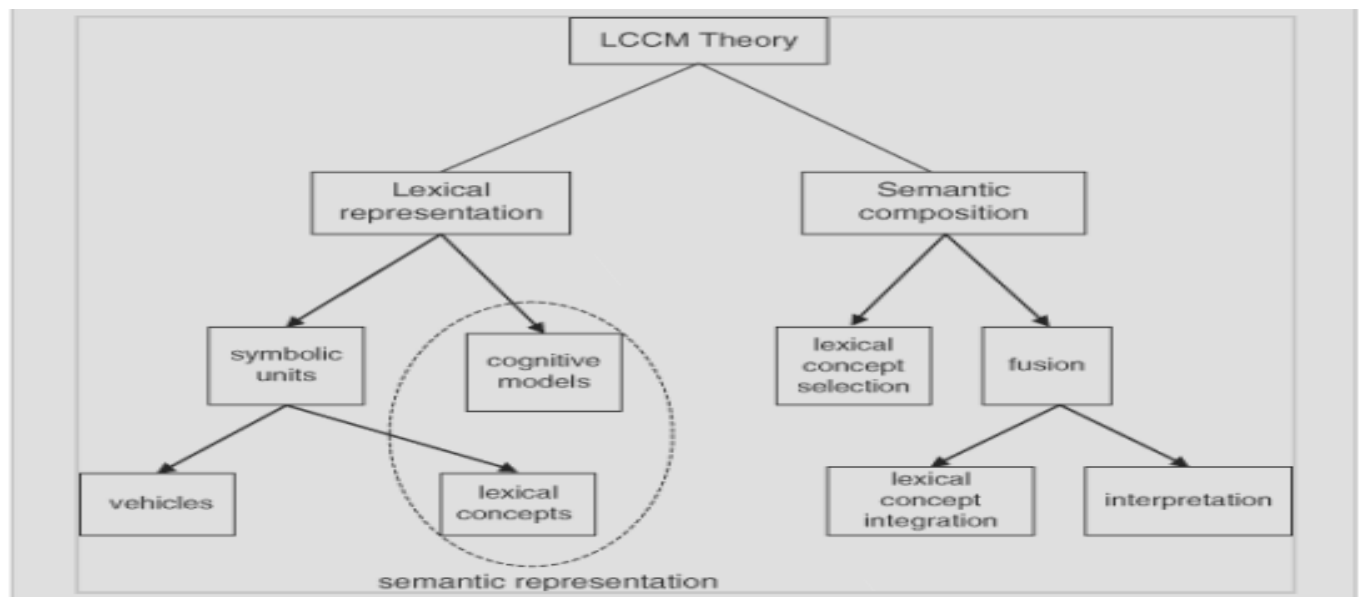

Figure 1. An overview of the architecture of LCCM Theory (Evans, 2009: 76)

Here are some key terms in the models.

Table 1. Key terms in LCCM

\begin{tabular}{|c|c|}
\hline Terms & Description \\
\hline Linguistic system & $\begin{array}{l}\text { The collection of symbolic units comprising a language, and the various } \\
\text { relationships holding }\end{array}$ \\
\hline Symbolic unit & A conventional pairing of a phonological form or vehicle and a semantic element \\
\hline Lexical concept & The semantic element that is paired with a phonological vehicle in a symbolic unit \\
\hline Linguistic content & $\begin{array}{l}\text { The type of content encoded by a lexical concept. This content is of a highly } \\
\text { schematic type that can be directly encoded in language }\end{array}$ \\
\hline Conce & $\begin{array}{l}\text { The body of non-linguistic knowledge captured from multimodal experience. This } \\
\text { knowledge derives from sensory-motor experience, proprioception and subjective } \\
\text { experience }\end{array}$ \\
\hline Cognitive model & $\begin{array}{l}\text { The representational form that knowledge in the conceptual system takes, as } \\
\text { modelled in LCCM Theory. Consists of frames which give rise to a potentially } \\
\text { unlimited set of simulations }\end{array}$ \\
\hline Conceptual content & The nature of the knowledge encoded by a cognitive model \\
\hline $\begin{array}{c}\text { Lexical } \\
\text { representation }\end{array}$ & $\begin{array}{l}\text { The primary substrate deployed in linguistically mediated meaning construction, } \\
\text { and modelled in terms of symbolic units and cognitive models }\end{array}$ \\
\hline $\begin{array}{c}\text { Semantic } \\
\text { representation }\end{array}$ & $\begin{array}{l}\text { The semantic dimension of lexical representations, consisting of semantic structure } \\
\text { and conceptual structure }\end{array}$ \\
\hline Semantic stru & $\begin{array}{l}\text { That part of semantic representation encoded by the linguistic system. Semantic } \\
\text { structure is modelled, in LCCM Theory, by lexical concepts. }\end{array}$ \\
\hline $\begin{array}{l}\text { Conceptual } \\
\text { structure }\end{array}$ & $\begin{array}{l}\text { That part of the semantic representation encoded by the conceptual system. } \\
\text { Conceptual structure is modelled, in LCCM Theory, by cognitive models }\end{array}$ \\
\hline
\end{tabular}


Part III of the book is to deal with semantic compositionality with two mechanisms of linguistically mediated usage events namely lexical concept selection and fusion. Lexical concept selection serves to identify the most appropriate lexical concept associated with a given form during the processing of an utterance. Fusion is the integrative process and results in the construction of a conception. This is achieved by recourse to two sorts of knowledge: linguistic content and conceptual content. Fusion is itself made up of two constituent processes: lexical concept integration and interpretation (see figure 2).

Chapter 14 and 15 comprise the fourth part which illustrates the way LCCM works on figurative language (metaphor and metonymy) and lexeme "time". Evans proves that literal meaning of an utterance is interpreted within the default or primary cognitive model profile while the nonliteral meaning must be understood in the secondary cognitive model profile. The distinction between metaphor and metonymy is due to the emergence of alignment between what were termed figurative target and figurative vehicle. In case of metaphor, there is divergence between the two while in case of metonymy, there is alignment. As for the semantics of lexeme "time", Evans presents a taxonomy of different sorts of linguistic expressions for the expression of time and then exploits LCCM to analyze the range of expressions addressed.

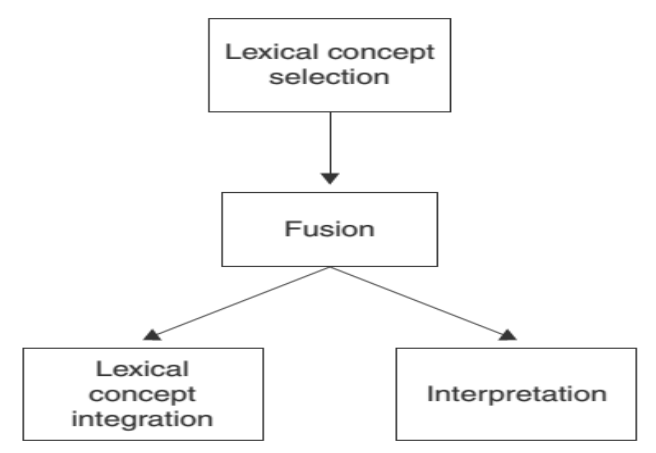

Figure 2. Processes of semantic composition in LCCM (Evans, 2009: 219)
The last chapter is for LCCM in context. It concludes the book and embeds LCCM Theory in the ensemble of other cognitive approaches to language. Evans also gives readers a glossary of terms ''that are either novel to LCCM Theory or which assume a special interpretation" (343). This glossary is of great significance as there are many new concepts to deal with while reading the book.

\section{Discussion}

Four authors have written reviews for the book so far (Crombach, 2010; Taylor, 2010; Murphy, 2011; Huttar, 2011). Within this review, instead of citing or justifying the evaluation of the above-mentioned reviewers; I focus on discussing the notion of polysemy in the light of LCCM.

Polysemy is an interesting phenomena of language and at least there are three approaches to it (Falkum and Vicente, 2015). While the rule-based and coercion accounts treat polysemy as linguistic phenomena, lexical pragmatic accounts downplay the contribution of the linguistic system and emphasise instead the communicative aspect of polysemy, treating it as being governed by pragmatic inferential processes applying at the level of individual words. The third account treats it as a cognitive one, and polysemy is the result of cognitive categories structured. Famous scholars of this account are Lakoff, Langacker, Brugman, Tyler, Taylor, Alliwood, Green and Evans.

At first, Evans from the very beginning chapter mentions that he follows the usagebased model of Langacker (2000), but in fact the examples in chapter 8 (and the whole book) are invented, or in other words, he mostly relies on his native sense of language. The small number of data may lead to ad hoc or even false analyses as shown by Taylor (2010) via the example of flying's category [SELFPROPELLED AERODYNAMIC MOTION]. From my perspective, Evans should have 
explained why the prepositions in, at, on in chapter 8 are polysemous, recalling that there are four types of readers of his book.

Secondly, I see that there is a need to differentiate different kinds of polysemy. Let's see the following sets of sentences.

Set 1

(1) The book is heavy.

(2) The book is long.

(3) The book is boring.

Set 2

(4) We are in a room.

(5) We are in love/ in pain/ in shock.

Set 3

(6) We are in love/shock/pain. 'state'

Cf. We are in a room. 'spatial'

(7). We are on alert best behaviour/lookout/the run. 'state'

Cf. We are on the sand. 'spatial'

In set 1 , book is conceptualized in different ways. In the first sentence, book is used to refer to a physical tome. In sentence 2 and 3 , book is exploited to denote a duration and a topic of uninterest. In light of LCCM, the polysemy in this case is the result of situated, sense-boundary construal, can be accounted for in terms of the cognitive model profile to which a lexical concept facilitates access.

In set 2, the preposition in in sentence 4 refers to a spatial relation of containment while in (5), the state sense are seen. The preposition in has distinct lexical concepts conventionally associated with it, i.e. a [PHYSICAL CONTAINER] lexical concept and a [PSYCHO-SOMATIC STATE] lexical concept. In this case, the preposition in is polysemous because there is a specific set of semantic and grammatical selectional tendencies associated with it ${ }^{(1)}$.

As for set 3, there is a shift of meaning from spatial to non-spatial. It is observed

\footnotetext{
1 We cannot say that the following sentence is grammatically correct "We are in war". This means that the preposition in is not compatible or can be used in any kind of abstract state.
}

from Evans' work in 2003, 2005, 2009; the state lexical concepts for the preposition in are different from those that are for on. The lexical concepts of the preposition in involve emotional or psychological force (in love, in pain). However, the lexical concepts of the preposition on, according to Evans, are instances of an [ACTIVE FUNCTIONING STATE] lexical concept (e.g., on duty, on sale, on the run, etc.).

\section{Conclusion}

In short, this is a well-structured, thoroughly analyzed book which provides readers with rich knowledge in terms of cognitive linguistics, psycholinguistics. This book is well worth reading and serves as a foundation for further research study on word meaning.

\section{References}

Allwood, J. (2003). Meaning potentials and context: some consequences for the analysis of variation in meaning. In: Cuyckens, H., Dirven, R., Taylor, J.R. (Eds.), Cognitive Approaches to Lexical Semantics (pp. 29-66). Berlin: Mouton de Gruyter.

Brugman, C. (1988). The Story of Over: Polysemy, Semantics, and the Structure of the Lexicon. Garland, New York.

Brugman, C., Lakoff, G. (1988). Cognitive topology and lexical networks. In: Small, S., Cottrell, G., Tannenhaus, M. (Eds.), Lexical Ambiguity Resolution: Perspectives From Psycholinguistics, Neuropsychology and Artificial Intelligence (pp. 477-507). Morgan Kaufman, San Mateo, CA.

Croft, William (2002). Radical Construction Grammar: Syntactic Theory in Typological Perspective. Oxford: Oxford University Press.

Crombach, Michael (2010). Review of V. Evans, How words mean. Available through http://linguistlist. org/issues/21/21-2636.html; Accessed 15/9/2017 $10: 13$.

Evans, V. (2005). The meaning of "time": Polysemy, the lexicon and conceptual structure. Journal of Linguistics, 41(1), 33-75.

Evans, V. (2013). Language and Time: A Cognitive Linguistic Approach. Cambridge: Cambridge University Press.

Evans and Green, Melanie (2006). Cognitive Linguistics: An Introduction. Edinburgh: Edinburgh University Press.

Goldberg, Adele (2006). Constructions at Work: The 
Nature of Generalization in Language. Oxford: Oxford University Press.

Falkum, I. \& Vicente, A. (2015). Polysemy: Current perspectives and approaches. Lingua, 157, 1-16.

Huttar, George (2011). Review of V. Evans, How words mean. Available through < https:/www.sil.org/ resources/publications/entry/48914 $>$ Accessed on 15/10/2017 18:26.

Lakoff, George and Johnson, Mark. (1980). Metaphors We Live By. Chicago: University of Chicago Press.

Lakoff, George and Johnson, Mark. (1999). Philosophy in the Flesh. New York: Basic Books.

Langacker, Ronald W. (1987). Foundations of Cognitive Grammar: Volume I Theoretical Prerequisites. Stanford: Stanford University Press.
Langacker, Ronald W. (2000). A dynamic usage-based model. In M. Barlow and S. Kemmer (eds), Usagebased Models of Language (pp. 1-64). Stanford, CA: CSLI Publications.

Murphy, Gregory L. (2011). Review of V. Evans, How words mean. Language, 87, 393-396. Available at $\quad<$ http://muse.jhu.edu/journals/language/ v087/87.2.murphy.html $>$ Accessed 30/6/2017 $13: 42$.

Taylor, John R. (2010). Review of V. Evans, How words mean. Journal of Linguistics, 46, 503-508.

Tyler, Andrea and Evans, Vyvyan (2003). The Semantics of English Prepositions: Spatial Scenes, Embodied Meaning and Cognition. Cambridge: Cambridge University Press. 